\title{
The Effect of Aspergillus fumigatus Infection on Antibody Immune Response to Newcastle Disease Virus in Broiler Chickens
}

\author{
Amer Khazaal Al-Azawy* and Karim Sadun Al-Ajeeli \\ Department of Microbiology, College of Veterinary Medicine, University of Diyala, Baquba, Diyala, Iraq \\ *Corresponding author's Email: amer_alazawy@ yahoo.com; ORCID: 0000-0002-4422-5442
}

Received: 22 Oct. 2019

Accepted: 29 Nov. 2019

\begin{abstract}
Aspergillus fumigatus infection might predispose birds to other respiratory infections with other pathogens such as Newcastle Disease Virus (NDV). This study aimed to investigate the incidence of Aspergillus fumigatus in commercial farms and its histopathological effects on respiratory organs and to evaluate the immunosuppressive effect of aspergillosis on NDV vaccinated birds. Aspergillus fumigatus was isolated from feedstuff and broilers in farms with respiratory manifestation. Twenty NDV-vaccinated broiler chickens of 10 days old were experimentally infected by feeding on feedstuff contaminated with Aspergillus fumigatus. Twenty vaccinated broilers but not fed the contaminated diet were used as the control group. Clinical signs, histopathological changes, NDV antibody levels in infected birds were recorded. Clinically, infected birds showed respiratory distress, dyspnea, gasping, ruffled feathers, green watery diarrhea, anorexia, lethargy, and unilateral drooping of wing. Histopathological changes were observed as disseminated granulomatous foci in the affected lungs, with caseous necrosis and leukocytes infiltration. The antibody immune response against NDV significantly reduced in infected birds compared with that of non-infected broilers. It is concluded, that Aspergillus fumigatus infection suppresses the immune responses and predisposes the broilers to other microbial infections, leading to considerable economic losses in the poultry industry.
\end{abstract}

Key words: Aspergillus fumigatus, Immunosuppression, NDV vaccine

\section{INTRODUCTION}

The genus Aspergillus belongs to a filamentous fungal group with wide dispersion in the environment and consists of approximately 200 species (Dagenais and Keller, 2009). Aspergillosis is a respiratory infection caused by fungi of the Aspergillus genus, in which Aspergillus fumigatus is the primary species responsible for infections in birds and mammals (Souza and Degernes, 2005). Regarding the types of aspergillosis, A. fumigatus is the most pathogenic organism causing brooder pneumonia in young chickens, turkeys, and waterfowl (Akan et al., 2002; Beytut et al., 2004; Cortes et al., 2005). Important economic losses are caused in young chicks and turkey infected with A. fumigatus (Lupo et al., 2010). Aspergillosis in birds could be initiated following the inhalation of large numbers of spores over a short period of time or chronic exposure to low levels of spores that are widely distributed in nature, thus birds frequently contact them through contaminated feed or litter, resulting in mycotic lesions in the respiratory tract (Arnè et al., 2011; Queiroz et al., 2013). The fungus spores are too small and can be able to reach the lungs and air sacs. The air sacs are usually the primary infection sites since inhaled air reaches the posterior thoracic and abdominal air sacs prior to contacting epithelial surfaces in the lungs (Nardoni et al., 2006). Although A. fumigatus is a ubiquitous and opportunistic fungal pathogen causing respiratory tract infections, other organs can also be involved. In addition, aspergillosis can affect many kinds of birds including chickens, turkeys, geese, ducks, quails, ostriches, parrots, canaries, pigeons, penguins and starlings (Cacciuttolo et al., 2009). Stress is a major predisposing factor for the development of the disease (Copetti et al., 2004). Inhalation of a large number of fungal spores is associated with a severe fungal infection that acted as a stress factor and suppresses immune responses due to the production of toxins such as gliotoxin (Gumussoy et al., 2004; Yokota et al., 2004). Aspergillosis occurs in commercial farms in two pathologic forms: acute outbreaks with high morbidity and high mortality found in newly hatched birds in particular and also in free-ranging fowls or psittacines under the poor sanitary or ventilation conditions following 
inhalation of the spores that lead to brooder pneumonia, whereas the chronic outbreaks found in adult birds (Tomee and Kauffman, 2000; Beernaert et al., 2010) and characterized by diffuse focal lesions in the viscera (Kunkle, 2003).

Newcastle disease is one of the most important viral diseases that cause severe economic losses in the poultry industry worldwide (MacLachlan and Dubovi, 2011). The causative agent of this disease is known as Newcastle Disease Virus (NDV) or Avian paramyxovirus 1. This virus has been recently classified into the genus Avian orthoavulavirus 1 within the subfamily Avulavirinae, this subfamily includes three genera, Orthoavulavirus genus, Paraavulavirus genus and Metaavulavirus genus in the family Paramyxoviridae (Dimitrov et al., 2019).

It has been reported that humoral immune responses are superior in protecting birds against virulent NDV isolates compared to cell-mediated immunity (Reynolds and Maraqa, 2000). Contrary, another report declared that resistance of birds to challenge with virulent strains after vaccination was associated with $\mathrm{T}$ memory cell stimulation, resulting in active lymphocytes that combat the disease (Miller and Koch, 2013).

Therefore, the current study investigated the incidence of aspergillosis in commercial farms based on microbiological isolation of A. fumigatus to study histopathological changes in organs of infected birds. In addition, this study assessed the immunosuppressive effect of Aspergillus fumigatus on NDV antibody titer in vaccinated broilers.

\section{MATERIALS AND METHODS}

\section{Ethical approval}

Scientific Ethical Committee approved the research and give the ethical number (Vet 14 Medicine November 2018 A and K).

\section{Sample collection}

During the periods from November 2018 to February 2019, 10 broiler flocks at Diyala province with heavy respiratory infections and high mortality rates were evaluated in this study. Infected chickens showed signs of gasping, dyspnea, green watery diarrhea, and anorexia. Randomly selected diseased birds were subjected to postmortem examination and swab samples were collected from infected organs and transferred to the microbiology laboratory for culturing. Samples were collected from poultry ration spoiled due to humidity and subjected to mycological examination.

\section{Samples processing}

All samples collected from birds and rations were cultured on Sabouraud Dextrose Agar (SDA) (Oxoid, Hampshire, UK) and incubated at room temperature for mycological examination. The fungal hyphae were stained with lactophenol cotton blue and examined with 40X lens under the light microscope (Baron and Finegold, 1990).

\section{Aflatoxin testing}

Feedstuff samples were collected from farms with brooder pneumonia and subjected to the Veterinary Laboratory of Baquba Veterinary Hospital, Diyala Province for aflatoxin testing.

\section{Broilers vaccination}

Forty one-day-old broiler chicks were supplied by local hatcheries. The birds were divided into two groups (A and B) of 20 birds each. They were separated completely from each other and fed with standard grower dry ration. At the age of 10 days, maternal antibodies against NDV were detected by ELISA kit (Synbiotic, USA) in nine birds randomly selected from each group. Thereafter, both groups of birds were vaccinated with the NDV vaccine (Clone 30, The Netherlands) delivered via drinking water at 10 days old.

\section{Experimental infection}

One day post-vaccination, 11-day-old broilers of group A fed with dry concentrated ration, whereas, group B fed with fungal contaminated feedstuff. The broilers in both groups were observed daily until the appearance of clinical signs.

\section{Post-infection sampling}

When respiratory clinical signs appeared, the postvaccination antibody level against NDV was estimated in both groups by collecting blood samples without anticoagulant. Serum samples were separated and antiNDV antibody titers were determined by the same abovementioned ELISA kit according to the manufacturer's instruction. Birds that showed severe respiratory signs were subjected to postmortem inspection for gross and histopathological examination. Samples from internal organs displaying lesions were immediately fixed with the $10 \%$ neutral buffered formalin to avoid the alteration of the tissues through autolysis, dehydrated in a graded ethanol series, cleared in xylene, embedded in paraffin following trimming and blocking in paraffin. Then 5-6 $\mu \mathrm{m}$ thick cross-sections were prepared and 
stained with Hematoxylin-Eosin (H\&E) according to the recommended procedure (Luna, 1968). Stained sections were viewed under an Olympus image analysis microscope and recorded (Olympic, Japan).

\section{Statistical analysis}

All data were analyzed using the SPSS software version 24 . The values less than 0.05 were considered significant.

\section{RESULTS}

The overall incidence of aspergillosis in 10 flocks was 70$90 \%$. These farms were poorly ventilated, overcrowded, and humid. Clinical signs and postmortem findings of affected birds clearly indicated aspergillosis. The flock history including location of the flock, population of birds per flock, age of birds, morbidity, and mortality rates are presented in table 1.

Table 1. Morbidity and mortality rates among broilers of commercial farms suspected of aspergillosis in different area of Diyala province, Iraq

\begin{tabular}{llcccc}
\hline Farm number & Location & Age of birds (day) & Number of bird & Morbidity rate & Mortality rate \\
\hline 1 & Baquba & 3 & 60004 & $80 \%$ & $50 \%$ \\
2 & Al-Mokdadia & 4 & 6000 & $90 \%$ & $70 \%$ \\
3 & Kanan & 6 & 5000 & $90 \%$ & $60 \%$ \\
4 & Baladrose & 5 & 7000 & $80 \%$ & $50 \%$ \\
5 & Al-Kales & 4 & 6000 & $76 \%$ & $50 \%$ \\
6 & BaqubaH & 10 & 7000 & $90 \%$ & $70 \%$ \\
7 & Baquba & 4 & 7000 & $90 \%$ & $70 \%$ \\
8 & Baquba & 5 & 7000 & $80 \%$ & $50 \%$ \\
9 & Al-Mansoria & 3 & 5000 & $90 \%$ & $70 \%$ \\
10 & Al-Mokdadia & 4 & 6000 & $90 \%$ & $70 \%$ \\
\hline
\end{tabular}

\section{Gross lesions}

The post-mortem examination of chicks showed numerous small white-yellowish caseous nodules $(<1 \mathrm{~mm}$ in diameter) and large roughly spherical granulomatous nodules $(>2 \mathrm{~cm}$ ) located in the lung (Figure 1). Similar lesions were observed on the surface of other tissues such as kidney, thoracic wall, and abdominal serosa. Nodules observed in the lungs and air sacs corresponded to acute aspergillosis lesions.

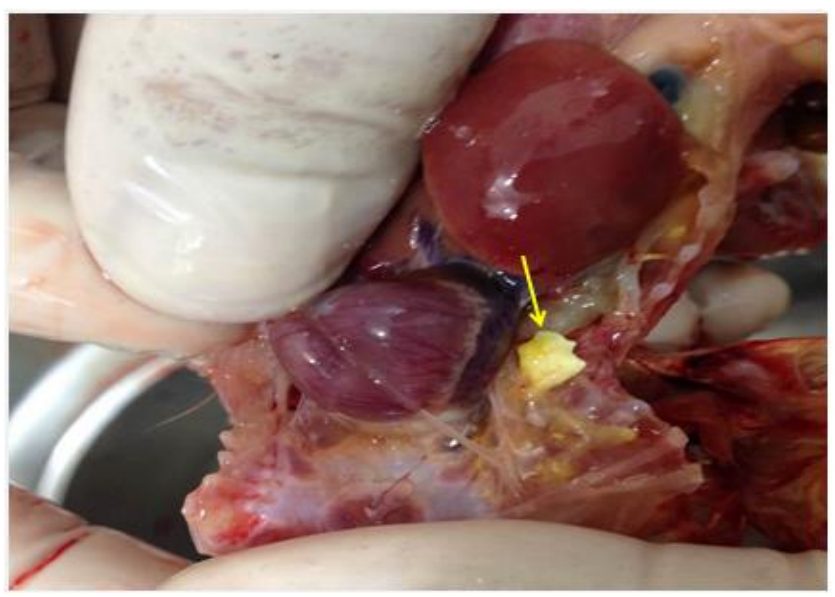

Figure 1. Creamy to yellow color nodules throughout the lung (arrow)

Culturing of swab samples from both infected organs and ration showed fungal growth obtained on day 5 postculture, with velvety gray to white colonies at first then turned to dark green (Figure 2 A). Fungal samples picked up from colonies and stained with Lactophenol cotton blue, microscopically showed sterigmata, septate hyphae bearing conidiophore vesicle, conidiophore, and chains of pigmented conidia. The conidiophore vesicle was incompletely covered with flask-shaped sterigmata (Figure 2B).

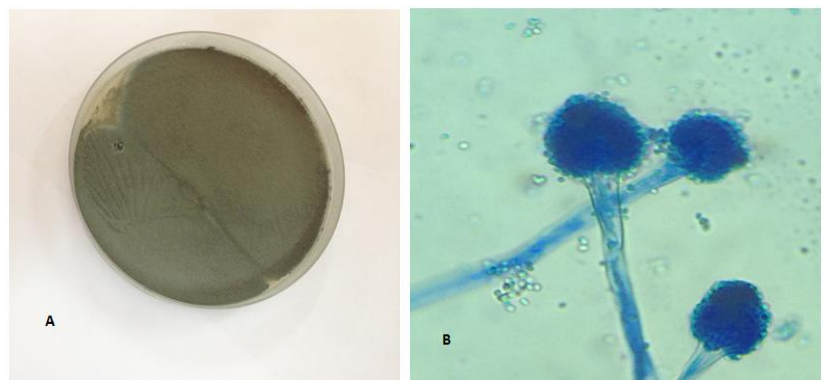

Figure 2. A: Grey-whitish color colony of Aspergillus fumigatus appeared on Sabaroud dextrose agar. B: Conidiophores with sphere-shaped or semispherical conidia (Lactophenol cotton blue staining).

\section{Aflatoxin detection}


The report of Baquba Veterinary Hospital indicated that the contaminated feed contained $43.7 \mathrm{ppb}$, which is considered a very high level of aflatoxin in poultry feedstuff.

\section{Experimentally infected broiler chickens}

Experimentally infected birds in group B showed the first clinical signs 3 days post-infection (PI) that developed quickly within the next 3 days when two birds died. General clinical signs observed in these birds were similar to those from clinical cases of 10 flocks, which included respiratory distress, dyspnea, gasping (Figure 3), ruffled feathers, green watery diarrhea, anorexia, stunting growth, lethargy, and unilateral drooping of the wing due to infection of the thoracic air sac.

Eight days post-infection, six birds died due to severe respiratory signs, and were subjected to postmortem examination and showed similar gross lesions mentioned in clinical cases of 10 flocks studied. These lesions were observed in the kidney, gizzard, and air sac (Figures 4, 5, 6 and 7). Histopathological examination of tissue samples from infected lungs showed disseminated granulomatous foci in tissue of the lung and air sacs. The center of the granulomatous foci contained caseous necrosis and necrotic cellular debris surrounded by rims of heterophils, lymphocytes, macrophages, and multinucleated giant cells. Also, vascular congestion was observed (Figure $8 \mathrm{~A}$ and B).

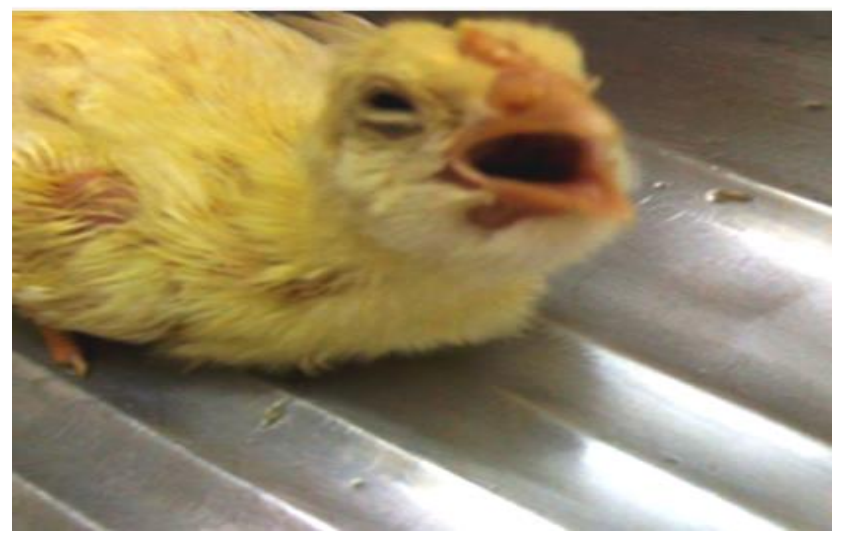

Figure 3. The signs of gasping and dyspnea in broiler chicken

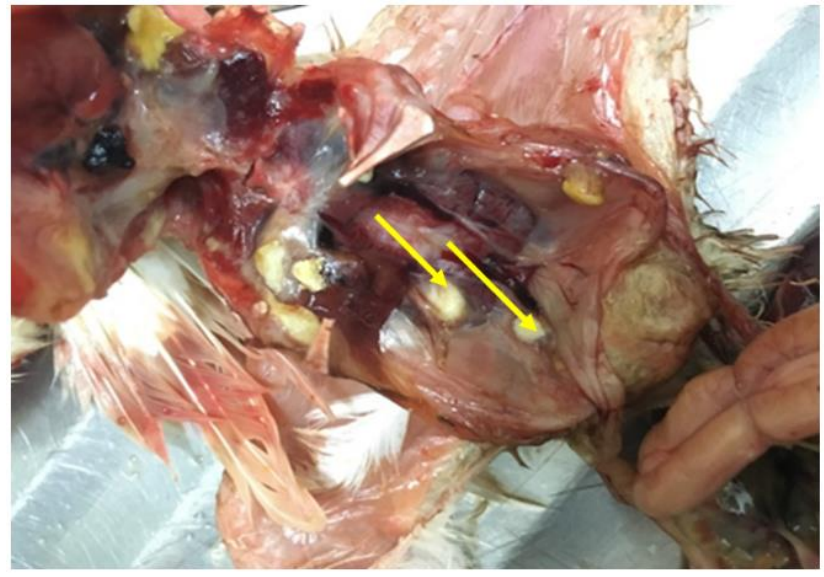

Figure 4. White-yellowish caseous nodules on the kidney.

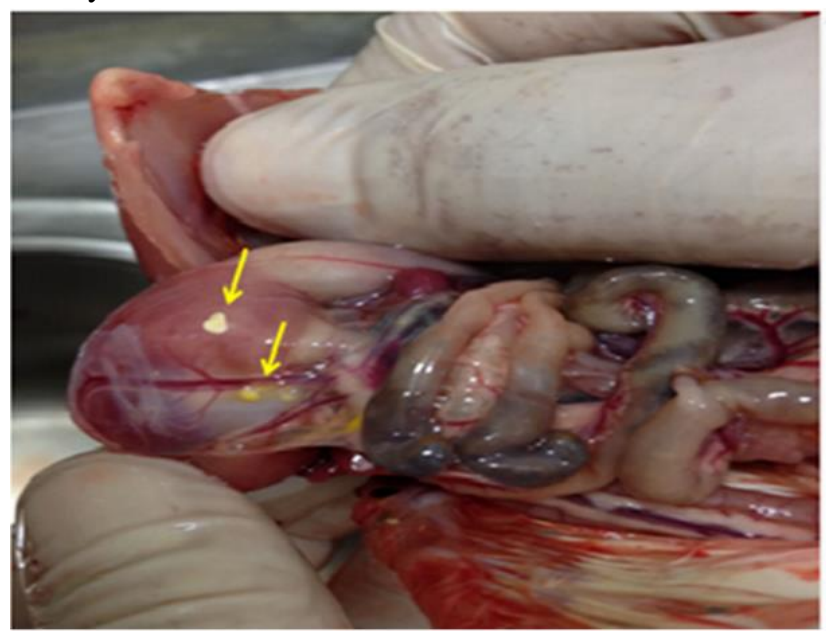

Figure 5. White-yellowish caseous nodules on the outer surface of the gizzard.

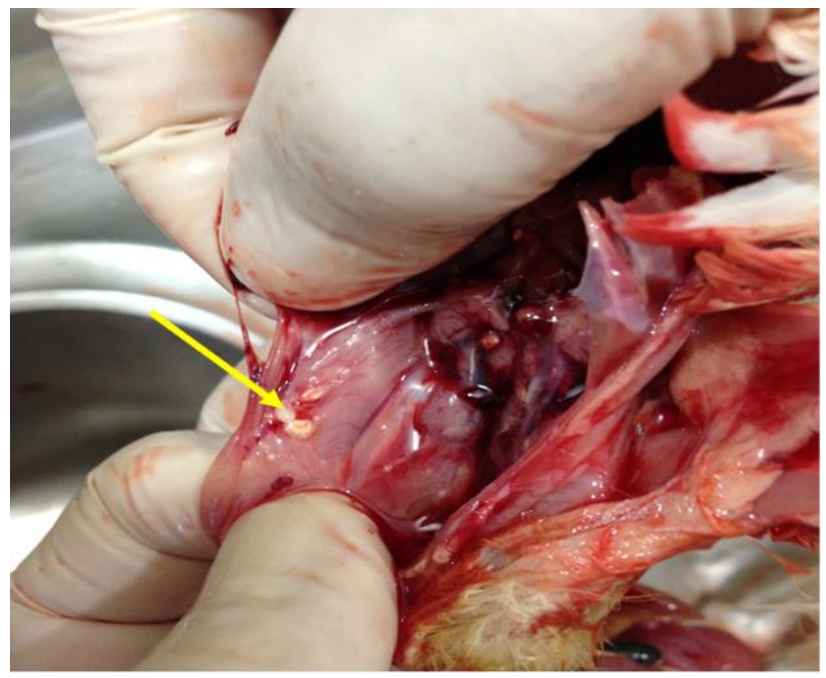

Figure 6. White-yellowish caseous nodules on the wall of thoracic air sac. 


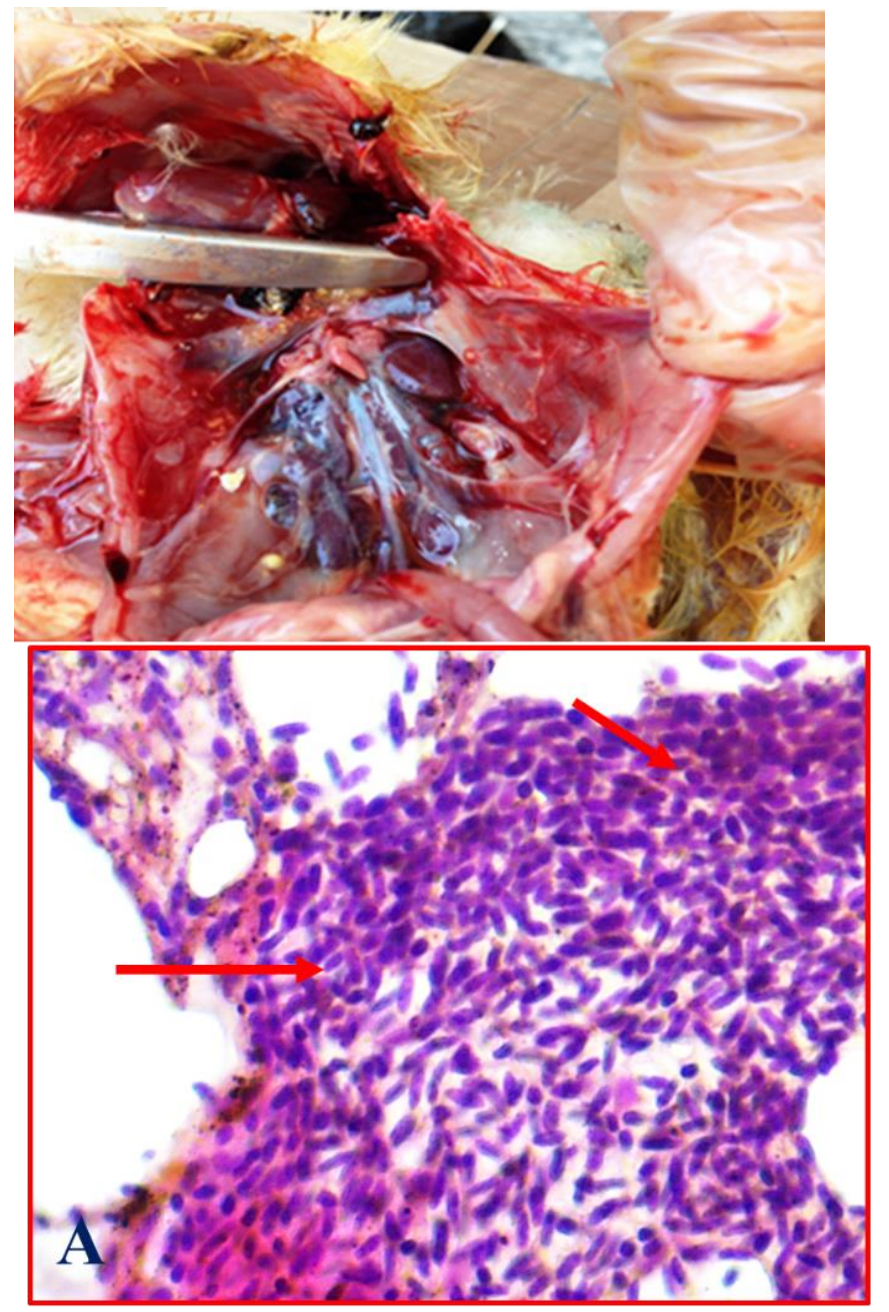

Figure 7. White-yellowish caseous nodules on the wall of the abdominal air sac.

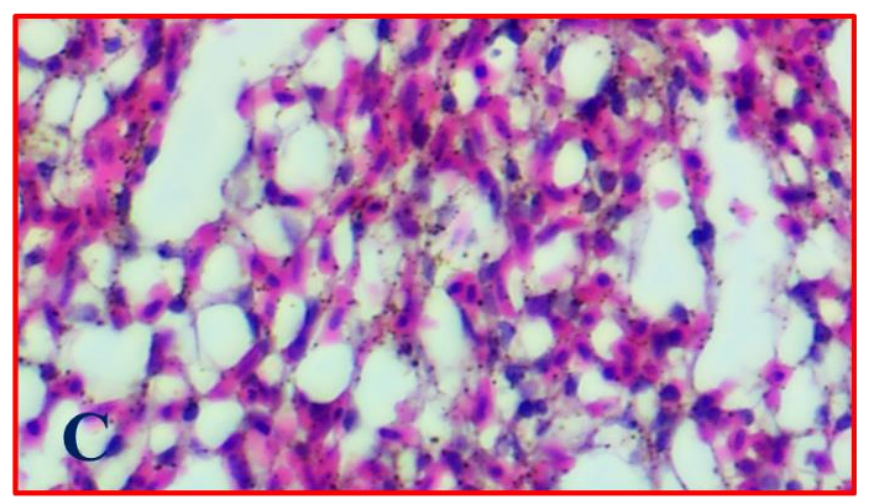

Figure 8. Lung tissues of broiler chickens with experimental aspergillosis. Granulomatous lesions with severe mononuclear cell aggregation in pulmonary tissues consist mainly of macrophage (A, red arrow) as well as vascular congestion (B, yellow arrow) comparing to normal lung (C). (40X, H\&E stain)

Aspergillus fumigatus was isolated from samples collected from affected organs of experimentally infected birds. Two birds died 3 days PI and were followed by the death of six birds 8 days PI. While 14 days PI another 10 birds died and only two birds survived. Broiler chicks of group A did not show any clinical signs and the birds survived until the end of the experiment.

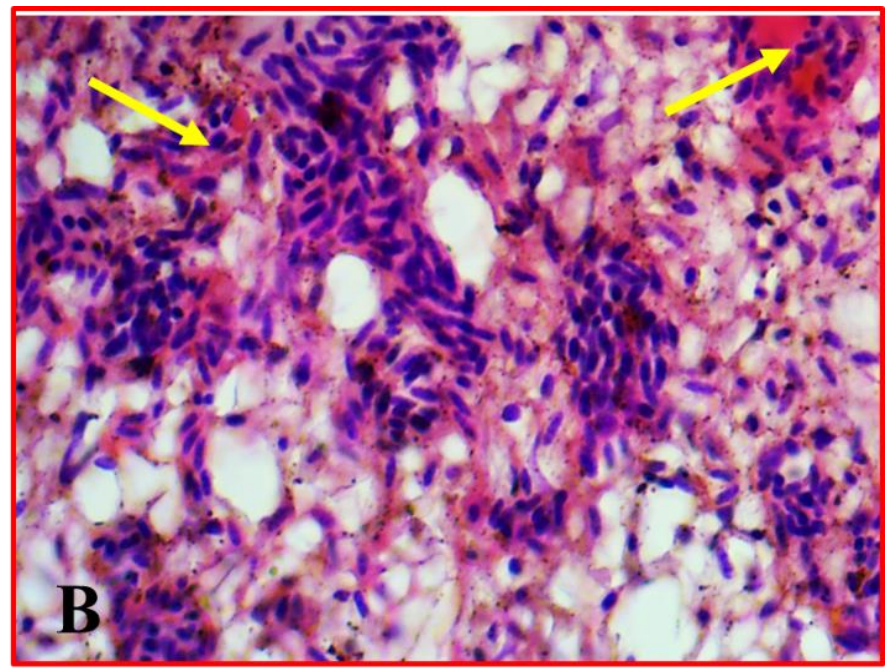
. 
antibodies post-vaccination. The mean antibody level was 10325.5 AU in group A and 3083.33 AU in group B (Table 2).

The comparison of maternal and post-vaccination antibody titers showed that the level of antibodies in the uninfected group was significantly $(\mathrm{p} \leq 0.05)$ higher than that of the fungi-infected group as well as the maternal antibodies.

Table 2. Determination maternal and post-vaccination antibody titers against Newcastle disease virus in fungi-infected and uninfected broiler chickens, Iraq

\begin{tabular}{|c|c|c|c|c|c|c|}
\hline Ab response to NDV & $\begin{array}{c}\text { No. of sampled } \\
\text { birds/ total birds }\end{array}$ & $\begin{array}{l}\text { Age of bird at time } \\
\text { of blood collection }\end{array}$ & Mean Ab & GMT & SD & $\% \mathrm{CV}$ \\
\hline Maternal $\mathrm{Ab}$ against NDV in group $\mathrm{A}$ and $\mathrm{B}$ & $18 / 40$ & 10 days old & $2298.11^{\mathbf{b}}$ & 1954 & 268.273 & 36.79 \\
\hline $\mathrm{Ab}$ titer against NDV 6 days PV in group A & $18 / 20$ & 16 days old & $10325.50^{\mathrm{a}}$ & 6165 & 4314.163 & 34.53 \\
\hline Ab titer against NDV 6 days PV in group $B$ & $18 / 20$ & 16 days old & $3083.33^{\mathbf{b}}$ & 1663 & 2172.733 & 53.20 \\
\hline
\end{tabular}

Group A: NDV vaccinated and uninfected broiler chickens. Group B: NDV vaccinated and fungi-infected broiler chickens. NDV: Newcastle disease virus, Ab: antibodies, AU: antibody unit, PV: post-vaccination, GMT: Geometric mean, SD: Standard deviation, CV: Coefficient of variation. No: number. Different superscript letters in a column indicate a significant difference $(p \leq 0.05)$.

\section{DISCUSSION}

In the present study, attempts were made to investigate the incidence of avian aspergillosis in commercial broiler farms at Diyala province. A similar incidence was described by Kapetanov et al. (2011) who reported the incidence of aspergillosis was more than $70-90 \%$ in most countries with tropical climate. Bhattacharya (2003) declared that aspergillosis occurs sporadically in wild birds but commonly in commercial farms.

Many species of Aspergillus including A. nidulus, $A$. flavus, A. niger can cause aspergillosis, but the most predominant cases are due to A. fumigatus which has very small spores in comparison to the spores of other Aspergillus fungi (Joseph, 2000; Beernaert et al., 2010; Tell et al., 2019).

The major clinical signs observed in both clinically and experimentally infected birds were moderate to severe respiratory distress, dyspnea and gasping, which are similar to those described by other researchers (Bhattacharya, 2003; Musa et al., 2014).

In the present study, remarkable lesions in postmortem examination were similar to those described by previous study (Musa et al., 2014) and clearly indicated aspergillosis, whereas Olson (1969) mentioned that diagnosis of Aspergillus in chickens based on clinical signs and postmortem findings is difficult because signs exhibited are non-specific and may be confused with other bird's infection.

The histopathological findings of the present study were in agreement with the other studies that revealed lesions in birds were commonly confined to lungs and air sacs and also reported the presence of caseous necrotic mass surrounded by inflammatory cells in nodular lesions (Yokota et al., 2004; Charlton et al., 2008).

In the present study, all samples cultured on SDA media were positive for A. fumigatus on the basis of colony characteristics (white colonies, at first, which turned dark green later). Ustimenko (1982) reported that the pure culture of A. fumigatus can be obtained from white to green mold growth on the walls of caseous thickened lungs and air sacs.

Broiler chicks infected with Aspergillus fumigatus had a lower level of anti-NDV antibodies than that in uninfected birds, indicating the infection with A. fumigatus led to the suppression of humoral immune responses to NDV. These results are consistent with the finding of many studies. Bellocchio et al. (2005) reported that $A$. fumigatus induced immune response of Th2 lymphocytes that had a role in immunosuppression, resulting in increased susceptibility to the infection and reduced survival. In addition, gliotoxin, a metabolite of $A$. fumigatus has the ability to suppress immune responses and cause apoptosis in primary and secondary lymphoid organs (Watanabe et al., 2003; Arné et al., 2011; Fouad et al., 2019). The concentration of gliotoxin in tissues of turkeys with airsacculitis was found to be $70 \mu \mathrm{g} / \mathrm{g}$ (Richard et al., 1996a), and the death of peripheral lymphocytes of those infected turkeys was attributed to high concentration of gliotoxin in their blood (Richard et al., 1994b; Arias et al., 2018).

Celik et al. (2000) reported impairment in the activity of $\mathrm{T}$ lymphocytes and macrophages phagocytosis in broilers affected by aflatoxin accumulation. Furthermore, Fontaine et al. (2011) found a new immunosuppressive metabolite of A. fumigatus composed of polysaccharide known as galactosaminogalactan. Its 
immunosuppressive activity promotes fungus development. Therefore, immune suppression due to fungal infection might predispose birds to other fungal, bacterial and viral infections (Javed et al., 2005).

\section{CONCLUSION}

Aspergillosis and aflatoxins suppress immune responses that may facilitate the infection of broilers with other microbial diseases. Further studies are needed to address factors associated with immunosuppression of infected birds in poultry farms.

\section{DECLARATION}

\section{Acknowledgment}

The authors would like to acknowledge the College of Veterinary Medicine University of Diyala for logistic supports. The authors also acknowledge the staff of molecular biology laboratory for timely help with guidance and support.

\section{Competing interests}

The authors declare that they have no competing interests.

\section{Authors' contributions}

Both authors contributed equally to this study and confirmed the final form of article.

\section{REFERENCES}

Akan M, Haziroglu M, Jlham Z, Sareyyupoglu B and Tunca R (2002). A case of aspergillosis in a broiler breeder flock. Avian Disease, 46: 497-501. DOI: https://doi.org/10.1637/0005-2086.

Arias M, Santiago L, Vidal-García M, Redrado S, Comas L, Lanuza PM, Comas L, Domingo MP, Rezusta A and Galvez EM (2018). Preparations for invasion: modulation of host lung immunity during pulmonary Aspergillosis by gliotoxin and other fungal secondary metabolites. Frontiers in immunology, 9: 2549. DOI: https://10.3389/fimmu.2018.02549.

Arné P, Thiery S, Wang D, Deville M, Le Loc'h G, Desoutter A, Féménia F, Nieguitsila, A, Huang W, Chermette R et al. (2011). Aspergillus fumigatus in Poultry. International Journal of Microbiology, DOI: https:doi.org/10.1155/.20111746356.

Baron EJ and Finegold SM (1990). Bailey and Scott's. Diagnostic Microbiology, 8th ed. St. Louis, MO: The C.V. Mosby Company, PP.76, 79, 82, 100-126, 133.
Beernaert LA, Pasmans LA, Van Waeyenberghe FL, Haesebrouck F and Martel A (2010). Aspergillus infections in birds: a review. Avian Pathology, 39(5): 325-333. DOI: https://doi.org/10.1080/03079457.2010.506210.

Bellocchio S, Bozza S, Montagoni C, Perruccios Gaziano R, Pitzurra L and Romani L (2005). Immunity to Aspergillus fumigatus: the basis for immunotherapy and vaccination. Medical Microbiology Supplement, 1(43):181-188. DOI: https://doi.org/10.1080/14789940500051417.

Beytut E, Ozcan K and Erginsoy S (2004). Immunohistochemical detection of fungal elements in the tissues of goslings with pulmonary and systemic aspergillosis. Acta Veterinaria Hungarica, 52: 71-84. DOI: https://doi.org/10.1556/avet.52.2004.1.8.

Bhattacharya A (2003). Aspergillus fumigatus infection in Khaki Campbell ducks in an organized duck farm in Tripura. Indian Veterinary Journal, 80(11): 1178- 1179.

Cacciuttolo E, Rossi G, Nardoni S, Legrottaglie R and Mani P (2009). Anatomopathological aspects of avian aspergillosis. Veterinary research communications, 33(6): 521-527. DOI: https://doi.org/10.1007/s11259-008-9199-7.

Celik I, Oguz H, Demet O, Dommez HH, Boydak M and Sur E (2000). Efficacy of polyvinyl polypyrrolydone in reducing the immunotoxicity of aflatoxin in growing broilers. Broiler Poultry Science, 41: 430-439. DOI: https://doi.org/10.1080/713654954.

Charlton BR, Chin RP and Barnes HJ (2008). Fungal infections. In: Diseases of poultry. Saif YM, Fadly AM, Glisson JR, McDougald LR, Nolan LK, and Swayne DE (Editors). 12th edition. Iowa State Press, Ames, Iowa. Pp. 989-1008.

Copetti MV, Segabinazi SD, Flores ML, Alves SH and Santurio JM (2004). Pulmonary aspergillosis outbreak in Rhea americana in Southern Brazil. Mycopathologia, 157: 269271. DOI:https://doi.org/10.1023/b:myco.0000024172.643 72.47

Cortes PL, Shivaprasad HL, Kiupel M and Senties-Cue G (2005). Omphalitis associated with Aspergillus fumigatus in poultry. Avian Disease, 49: 304-308. DOI: https://doi.org/10.1637/7300-110304r.

Dagenais TR and Keller NP (2009). Pathogenesis of Aspergillus fumigatus in invasive aspergillosis. Clinical Microbiology Reviews, 22(3): 447-465. DOI: https:// doi.org/10.1128/cmr.00055-08

Dimitrov KM, Abolnik C, Afonso CL, Albina E, Bahl J, Berg M, Briand FX, Brown IH, Choi KS, Chvala I and Diel DG (2019).Updated unified phylogenetic classification system revised nomenclature for Newcastle disease virus. Infection, Genetic and Evolution. DOI: https://doi.org/10.1016/j.meegid.2019.103917

Fontaine T, Delangle A, Simenel C, Coddeville B, van Vliet SJ, van Kooyk Y, Bozza S, Moretti S, Schwarz F, Trichot $C$ et al. (2011). Galactosaminogalactan, a new immunosuppressive polysaccharide of Aspergillus fumigatus. PLoS Pathogens, 7(11): e1002372. DOI: https://doi.org/10.1371/journal.ppat.1002372. 
Fouad AM, Ruan D, El-Senousey HK, Chen W, Jiang S and Zheng C (2019). Harmful effects and control strategies of aflatoxin b1 produced by Aspergillus flavus and Aspergillus parasiticus strains on poultry. Toxins, 11(3): 176. DOI: https:// doi.org/10.3390/toxins11030176

Gümüşsoy KS, Uyanik F, Atasever A and Cam Y (2004). Experimental Aspergillus fumigatus infection in quails and results of treatment with itraconazole. Journal of Veterinary Medicine, 51(1): 34-38. DOI: https://doi.org/10.1046/j.1439-0450.2003.00720.x .

Javed TD, Ombrink-Kurtzman MA, Richard JL, Bennet GA, Cote LM and Buck WB (2005). Serohematologic alterations in broiler chicks on feed amended with Fusarium proliferatum culture material or fumonisin B1 and moniliformin. Journal of Veterinary Diagnosis Investigation, 7: 520-526. DOI: https://doi.org/10.1177/104063879500700417 .

Joseph V (2000). Aspergillosis in raptors. Seminars in Avian and Exotic Pet Medicine, 9: 66-74. DOI: https://doi.org/10.1053/AX.2000.4617.

Kapetanov M, Potkonjak D, Milanov D, Stojanov I, Zivkov Balos $M$ and Prunic B (2011). Investigation of dissemination of aspergillosis in poultry and possible control measures. Zbornik Matice srpske za prirodne nauke, 120: 269-278. DOI: https://doi.org/10.2298/zmspn1120269k .

Kunkle RA (2003). Aspergillosis. In: Y M Saif, H J Barnes, J R Glisson et al. (Editors), Diseases of Poultry, Iowa State University Press, Ames, Iowa, USA, pp. 883-895. DOI: https://doi.org/10.1002/9781119421481.ch7 .

Luna LG (1968). Manual of Histologic Staining Methods of the Armed Forces Institute of Animals, 3rd edition. McGrawHill Book Company. New York. DOI: https://doi.org/10.1002/sce.3730520129 .

Lupo C, Le Bouquin S, Allain V, Balaine L, Michel V, Petetin I and Chauvin C (2010). Risk and indicators of condemnation of male turkey broilers in western France, February-July 2006. Preventive Veterinary Medicine, 94(3-4): 240-250. DOI: https://doi.org/10.1016/j.prevetmed.2010.01.011 .

MacLachlan NJ and Dubovi EJ (2011). Fenner's Veterinary Virology. 4th edition, pp. 299-325. Academic Press. ELSEVER. DOI: https://doi.org/10.1016/b978-0-12375158-4.00017-1.

Miller PJ and Koch G (2013). Newcastle Disease. In: Swayne DE, Glisson JR, McDougald LR, Nolan IK, Suarez DL, Nair V (Editors.), Disease of Poultry. Wiley-Blackwell Hoboken, New Jersey, pp. 89-138. DOI: https://doi.org/10.1002/9781119371199.

Musa IW, Aliyu G and Ismail A (2014). Aspergillosis in Broilers: Reports of three cases from a commercial and two Broiler Breeder farms in Zaria, Nigeria. International Journal of Current Microbiology and Applied Sciences, 3(6): 932-938. Available at: http://www.ijcmas.com.
Nardoni S, Ceccherelli R, Rossi and Mancianti F (2006). Aspergillosis in Larus cachinnans micaellis: survey of eight cases. Mycopathologia, 161: 317-321. DOI: https://doi.org/10.1007/s11046-006-0012-2 .

Olson L (1969). Aspergillosis in Japanese quail. Avian disease, 13: 225-227. DOI: https://doi.org/10.2307/1588433 .

Queiroz B, Pereyra CM, Keller KM, Almeida T, Cavaglieri CE Magoli CE and da Rocha Rosa CA (2013). Fungal contamination and determination of fumonisins and aflatoxins in commercial feeds intended for ornamental birds in Rio de Janeiro, Brazil. Online Litters in Applied Microbiology (C) The Society for Applied Microbiology, DOI: https://doi.org/10.111/larm.12127.

Reynolds DL and Maraqa AD (2000). Protective immunity against Newcastle disease: the role of cell mediated immunity. Avian Disease, 44: 145-154. DOI: https://doi.org/10.2307/1592518 .

Richard JL, Dvorak TJ and Ross PF (1996a). Natural occurrence of gliotoxin in turkeys infected with Aspergillus fumigatus, Fresenius. Mycopathologia, 134(3):167-170. DOI:https://doi.org/10.1007/bf00436725.

Richard JL, Peden WM and Williams PP (1994b). Gliotoxin inhibits transformation and it's cytotoxic to turkey peripheral blood lymphocytes. Mycopathologia, 126 (2):109-114. DOI: https://doi.org/10.1007/bf01146202.

Souza M J and Degernes LA (2005). Prevalence of aspergillosis and distribution of lesions in wild swans in Northwest Washington State, 2000-2002. Journal Avian Medicine and Surgery, 19 (2): 98-106. DOI: https://10.1647/2004-001

Tell LA, Burco JD, Woods L and Clemons KV (2019). Aspergillosis in Birds and Mammals: Considerations for Veterinary Medicine. In: Recent Developments in Fungal Diseases of Laboratory Animals,pp. 49-72. Springer, Cham. DOI: https://10.1007/978-3-030-18586-2_4

Tomee JF and Kauffman HF (2000). Putative virulence factors of Aspergillus fumigatus.: Journal of the British Society for Allergy and Clinical Immunology, 30(4): 476-484. DOI: https://doi.org/10.1046/j.1365-2222.2000.00796.x .

Ustimenko AN (1982). Aspergillosis of fowls and sanitary condition of incubators in U.S.S.R. Poultry Abstract, 8(4): 138. DOI: https://doi.org/10.1016/s0033-3506(05)807802 .

Watanabe , Kuriyama T, Kamei , Nishimura K, Miyaji M, Sekine $\mathrm{T}$ and Waku M (2003). Immunosuppressive substances in Aspergillus fumigatus culture filtrate. Journal of Infection and Chemotherapy, 9(2): 114-121. DOI: https://doi.org/10.1007/s10156-002-0227-1.

Yokota T, Shibahara T, Wada Y, Hirak IR, Ishikawa Y and Kadota K (2004). Aspergillus fumigatus infection in an ostrich (Struthio camelus). Journal Veterinary Medicine Science, 66: 201-204. DOI: https://doi.org/10.1292/jvms.66.201. 